REVISTA DE DERECHO UNED, NÚM. 26, 2020

\title{
MATRIMONIOS ILEGALES, INEXISTENTES O NULOS, DESDE LA LEGISLACIÓN MATRIMONIAL DE AUGUSTO HASTA CONSTANTINO I
}

\author{
ILLEGAL MARRIAGES, INEXISTING OR NULL, \\ FROM THE MARRIAGE LEGISLATION FROM AUGUSTO \\ UNTIL CONSTANTINO I \\ Elisa Muñoz CatALÁN \\ Doctora en Derecho, Premio extraordinario de Doctorado \\ Tutora con venia docencia. UNED \\ Doctora en Derecho acreditada \\ Universidad Internacional de La Rioja - España \\ elisa.munoz@unir.net
}

Resumen: Con el presente trabajo de investigación hemos analizado la importancia de las leyes matrimoniales promulgadas por el emperador Augusto, su idea de romanidad, así como la posterior evolución postclásica ya con Constantino I. En este sentido, se ha demostrado cómo tanto la Lex Iulia de maritandis ordinibus como la Lex Papia Poppaea nuptialis formaron un solo texto denominado Lex Iulia et Papia Poppaea cuya finalidad fue la restauración de la familia sobre la base de las tradiciones para desarrollar una política que favoreciese las uniones lícitamente contraídas y la procreación. Lo anterior nos llevará a reparar en los matrimonios romanos ilegales, esto es, aquellas uniones conyugales carentes del conubium que no producían efectos jurídicos y se consideraban como un matrimonium iniustum. Finalmente, hemos preferido diferenciar entre los matrimonios iniustum inexistentes y los nulos o ineficaces porque presentan supuestos distintos y en las fuentes no existe una diferenciación clara. 
Palabras clave: matrimonio romano, ilegal, impedimento, leyes matrimoniales, Augusto.

Abstract: With this research we have analyzed the importance of matrimonial laws promulgated by emperor Augustus, his idea of romanity, as well as the subsequent post-classical evolution already with Constantine I. In this sense, it has been demonstrated how both the Lex Iulia de maritandis ordinibus and the Lex Papia Poppaea nuptialis formed a single text called Lex Iulia et Papia Poppaea whose purpose was the Restoration of the family on the basis of traditions to develop a policy that favored lawfully contracted unions and procreation. This will lead us to repair illegal roman marriages, that is, those marital unions lacking conubium and, therefore, did not produce legal effects and were considered as a matrimonium iniustum. Finally, we have preferred to differentiate between non-existent iniustum marriages and null or ineffective marriages because they present different assumptions and in the sources there is no clear differentiation.

Key words: roman marriage, illegal, impediment, matrimonial laws, Augustus.

Recepción original: 27-11-2020

Aceptación original: 8-6-2020

Sumario: I. INTRODUCCIÓN; II. LA LEGISLACIÓN MATRIMONIAL DEL EMPERADOR AUGUSTO ANTE LA IDEA DE "ROMANIDAD"; II. A. Antecedentes; II. B. Análisis jurídico del contenido de las leyes augústeas y sus prohibiciones matrimoniales; III. DEROGACIÓN PARCIAL DE LAS LEYES MATRIMONIALES CON EL EMPERADOR CONTANTINO I; IV. HACIA UNA CLASIFICACIÓN DE LOS MATRIMONIOS ROMANOS ILEGALES INEXISTENTES O NULOS; IV. A. Matrimonium iniustum inexistente o non potest; IV. B. Matrimonium iniustum nullum; V. NATURALEZA JURÍDICA DE LAS PROHIBICIONES A CONTRAER IUSTAE NUPTIAE E IMPEDIMENTOS; VI. CONCLUSIONES; VII. REFERENCIAS BIBLIOGRÁFICAS; VII. A. Bibliografía; VII. B. Fuentes legislativas y/o electrónicas.

\section{INTRODUCCIÓN}

La aportación de una clasificación completa que reúna los diferentes tipos de prohibiciones matrimoniales que existieron en Roma, entendemos que debe de ir precedida de un estudio detallado 
de la evolución de las fuentes jurídicas que regulan la materia, así como de las reformas familiares y matrimoniales introducidas por los emperadores en las distintas etapas históricas del Derecho Romano. De este modo y, mediante una revisión de la literatura existente en la materia y las fuentes al respecto, el análisis de la legislación matrimonial clásica va a resultar clave en nuestro trabajo debido no sólo a la finalidad que estas normas pretendieron sino también por la figura del emperador Augusto quien introdujo numerosas reformas sociales a través de sus leyes matrimoniales ${ }^{1}$. Entre éstas destacamos, de modo genérico, la restauración de las tradiciones morales del pueblo romano, la integridad del matrimonio como institución, y la recuperación de los antiguos festivales religiosos.

Para entender el alcance jurídico de la legislación augústea y su evolución hasta llegar al emperador Constantino I, hemos considerado necesario realizar a lo largo de nuestro estudio una primera aproximación hacia el contexto social, político y económico en el que se desenvuelven estas normas matrimoniales, para a continuación analizar jurídicamente su evolución en las diferentes fases del Imperio Romano. Sin olvidar, en cualquier caso, que Augusto fue el creador de un conjunto de principios reguladores del matrimonio, que se distinguen de los demás, por su carácter unitario y completo, y por basarse en una serie de costumbres que sirvieron de reglas de conducta y de fuentes del derecho perfectamente aplicables.

Sin más, comenzamos nuestro estudio analizando el contexto en el que se desenvuelve la legislación matrimonial de Augusto para realizar un análisis detallado de su alcance legal en lo que se refiere al tema de las limitaciones a contraer matrimonio durante la época del Principado y su posterior evolución, teniendo en cuenta las distintas posturas doctrinales. Para acabar con este apartado, veremos la derogación parcial de esas leyes matrimoniales que hace el emperador Constantino I y su influencia para el Derecho Romano tardío. En cualquier caso, se suele admitir que las prohibiciones matrimoniales que vamos a mostrar en nuestra investigación conllevan en la época clásica la no existencia del matrimonio -debido a la inexistencia de conubium entre ambas partes- y la nulidad en tiempo postclásico, en los términos que hemos señalados².

1 Para un análisis más exhaustivo de las leyes matrimoniales de Augusto, nos remitimos a: MALDONADO DE LIZALDE, E. "Lex Iulia de Martindais Ordinibus. Leyes de familia del emperador César Augusto», UNAM, pp. 535-645 [En línea]: http://historico.juridicas.unam.mx/publica/librev/rev/hisder/cont/14/dr/dr13.pdf

2 NÚÑEZ PAZ M. I., Consentimiento matrimonial y divorcio en Roma, Salamanca (Ediciones Universidad de Salamanca), 1988, p. 37. 
Teniendo presente que en España aún hoy no existe una legislación matrimonial específica, sino que tenemos que acudir a las disposiciones contenidas en el Código Civil español (artículos 42-107) y a ciertas leyes que lo desarrollan en algunos aspectos, nos puede servir para iniciar este estudio matrimonial las palabras del jurista Gayo quien definía al matrimonio romano clásico como aquella situación de hecho (res facti), con relevancia jurídica y carente de prohibición alguna para contraer justas nupcias, que resulta de la convivencia de un ciudadano romano con mujer romana, como maritus y uxor, y entre los que existe recíproco consentimiento ${ }^{3}$.

\section{LA LEGISLACIÓN MATRIMONIAL DEL EMPERADOR AUGUSTO ANTE LA IDEA DE “ROMANIDAD”}

\section{A. Antecedentes}

La evolución del derecho matrimonial vigente durante la segunda etapa clásica o, también conocida, como "etapa clásica alta o central" (del 30 a.C. al 130 d.C.) viene marcada por el tránsito de la forma política Republicana al Principado de Augusto. La situación social, política y económica de este periodo se caracteriza por una serie de circunstancias que rodearon a la fase final de la República, que seguidamente detallamos. En primer lugar, la degeneración y tendencia al desorden. En este contexto, Gómez (1987) en su obra nos muestra de qué manera la gran acumulación de riquezas, la ociosidad de la paz tras largas luchas sociales y civiles, las conmociones de todo tipo propias de una época de grandes conquistas, habían destruido final y definitivamente, los viejos principios de ética y moral que en gran medida soportaban, de una u otra manera, las bases de la familia romana.

En segundo término, se produce una depauperación de las familias pertenecientes a las clases más elevadas y, como consecuencia de este empobrecimiento, la institución familiar que había sido un núcleo indisoluble, pasa a un segundo plano para hacer surgir nuevos estratos sociales centrados más en la riqueza que en su ascendencia familiar. A lo anterior se añade el hecho de que muchos libertos, con la intención de salir de su clase social y de aportar riqueza al Estado con su actividad, pasaron a formar parte de la burguesía y del funcionariado imperial. Así, los caballeros se habían enriquecido

3 Sobre el texto completo y original del jurista: Gai. 1,57: Legitimae sunt nuptiae, si Romanus Romanam nuptiis intervenientibus vel consensu ducat uxorem. 
y quisieron ennoblecer su estirpe dedicándose a profesiones tradicionalmente aristócratas, como la de políticos o terratenientes. Por su parte, la clase patricia había aumentado considerablemente su número.

En el aspecto social y económico, observamos cómo durante el siglo II a.C. a la anteriormente nombrada destrucción de las familias de las clases más elevadas, se une hechos tan determinantes como: el elevado número de guerras, el otorgamiento de libertad a muchos esclavos (quienes normalmente se convertían en ciudadanos romanos, aun cuando no compartían las virtudes del cives tradicional, ni respondían a los mismos esquemas morales ni valores éticos que investían a un ciudadano romano), el caos económico derivado de las luchas, y la grave decadencia de las costumbres, ya que se produjo un olvido tanto de los mores maiorum como de los ideales y virtudes tradicionales del pueblo romano. En este punto, la tarea del emperador Augusto consistió en dictar normas unilaterales sin intervención del pueblo romano para recuperar el orden moral perdido, pues el mismo se encontró con un desorden generalizado en todas las instituciones, al que tuvo que hacer frente durante la época de mayor esplendor del Imperio. La reforma de Augusto no se basaba en un ideal de perfección ética, como sucederá posteriormente con la llegada del Cristianismo, sino más bien en la restauración de las costumbres que habían caracterizado al pueblo romano a través de nuevas leyes demográficas y matrimoniales. Éstas favorecieron la recuperación del orden moral y social perdido pero fueron gravemente restrictivas de la libertad y derechos de los cives.

Bajo este contexto y, antes de pasar a analizar detalladamente la reforma de Augusto y las prohibiciones matrimoniales, consideramos imprescindible aclarar la idea de romanidad inserta en las leyes del emperador. Así, el origen latino del sustantivo "romanidad" lo encontramos en la palabra Roma, esto es, Roma como capital del Imperio fundada por Rómulo en el año 754 a.C. y en romanus-a-um, del adjetivo romano, de Roma o referente a Roma (como cives romanus o populus romanus). En ambos casos, se hace referencia al deseo de Augusto por alcanzar el restablecimiento de los mores o costumbres en el ámbito de la familia y al interés por el crecimiento demográfico y la selección de la población para detener la fuerte corriente de extranjeros que se iban infiltrando entre los cives.

A tenor de lo expuesto, el emperador Augusto pretendía no sólo aumentar el número de nacimientos sino que, de forma paralela, quería que los nacidos fuesen ciudadanos genuinamente romanos. De ahí la idea de romanidad para hacer como una especie de raza 
pura de los ciudadanos que efectivamente cumpliese con las condiciones establecidas para ser cives, y como nos recuerda a lo largo de su trabajo el profesor Gómez (1987) con todas las virtudes propias de aquellos ciudadanos de Roma que hicieron posible la grandeza, expansión y hegemonía universal de otros tiempos. A ello se añade el intento de restaurar la familia romana sobre la base de las tradiciones y de los mores maiorum para desarrollar una política legislativa que favoreciera las uniones matrimoniales lícitas. Durante este periodo histórico el Derecho de Familia adquiere un carácter humano alejándose de las etapas anteriores y configura al matrimonio como una unión libre y disoluble en la que viven ambos cónyuges en pie de igualdad.

En esta línea, nos preguntamos cuáles son los resultados de esta política llevada a cabo por el emperador. La idea de romanidad se demuestra si tenemos en cuenta que, si bien en el año 28 a.C. el censo sólo contaba con unos 4.066 .000 ciudadanos, cinco años después con el consulado de Censorino, el número aumentó a 4.230.000 y, un lustro más tarde, pasó a 4.937 .000 cives. Tales incrementos de población debieron ser escasos e insuficientes para Augusto, pues en el año 18 a.C., hizo aprobar por los Comicios la conocida Lex Iulia de Maritandis ordinibus que, con la sucesiva Lex Papia Poppaea del 9 a.C., constituyen una completa legislación demográfica, dirigida al fin primordial de favorecer la natalidad. En suma, podemos mostrar la romanidad perseguida por el emperador Augusto en los siguientes puntos:

a) Romanidad en cuanto a las leyes: Las leyes augusteas impulsaron el crecimiento demográfico y la procreación, pero siempre que las uniones entre cives romanus fuesen calificadas como matrimonium iustum por el ordenamiento jurídico.

b) Romanidad en cuanto a la política llevada a cabo: De este modo, indirectamente, se desarrolló una política legislativa que favorecía los vínculos matrimoniales frente a otro tipo de uniones menos reconocidas por el derecho. Para ello, trataron de restaurar una institución tan importante como la familia romana sobre la base de las antiguas tradiciones.

c) Romanidad en cuanto a los hijos nacidos: Sólo los nacidos de tales uniones lícitamente contraídas eran tenidos en cuenta para que sus padres pudieran gozar de los beneficios que las leyes otorgaban, estableciéndose limitaciones y desventajas tanto a los solteros (caelibes) como a los huérfanos (orbi). 
d) Romanidad en cuanto a la libertad: Augusto se encontró con que las ideas de libertad y desarrollo de la personalidad estaban profundamente arraigadas y ello se manifestaba, por ejemplo, en la fácil y consensual disolución del vínculo conyugal; asimismo, esta libertad se transformó en libertinaje ante aquellos cambios sociales que la Aristocracia romana no había sido capaz de asimilar.

De ahí que el emperador tratase de realizar una política demográfica y social nueva, gracias a las dos leyes matrimoniales que se encontraban no sólo cercanas en el tiempo sino también eran parecidas en las materias tratadas, como son: matrimonio e impedimentos, divorcio, dote, donaciones entre cónyuges, concubinato, herencia y legados, etc. Sobre los efectos jurídicos que produce la romanidad, el profesor Puchta (1875) sostuvo hace tiempo que estas dos leyes son el monumento legislativo más importante, considerable y extenso del Derecho Romano después de la XII Tablas. Sin embargo, otros autores lo califican de fracaso legislativo porque ni siquiera consiguieron el objetivo principal del incremento de nacimientos en las clases altas. De este modo, Del Castillo (1976) a lo largo de su obra afirma expresamente que son un total y catastrófico fracaso. En cualquier caso, en nuestra investigación, partimos de la premisa general de que, si bien estas normas no alcanzaron la finalidad inicialmente pretendida por Augusto, no es menos cierto que sirvieron de base para regular el matrimonio y los impedimentos al mismo, en una época en la que no existían más fuentes que las costumbres de los antepasados. Consideramos, por ende, que en todo caso estas leyes matrimoniales son una pieza clave para el Derecho Romano clásico y no tienen parangón frente a otras fuentes jurídicas.

\section{2. Análisis jurídico del contenido de las leyes augústeas y sus prohibiciones matrimoniales}

Como avanzábamos, la mayor parte de la doctrina es unánime al afirmar que las leyes augusteas no eran perfectas pero si lograron regular aspectos impensables hasta entonces, este hecho se debe a la misma realidad romana pues las escasas normas que existían tenían un carácter restrictivo o impeditivo y, por este motivo, pertenecían a la categoría de minus quam perfectae ${ }^{4}$. Por tanto, no podemos enten-

4 Sobre la calificación de leyes imperfectas, vid. RUIZ, A., Historia del Derecho Romano, Madrid, 1980, p. 169 en GÓMEZ RUIZ, C., El Divorcio y las Leyes

(C) UNED. Revista de Derecho UNED, núm. 26, 2020 
der una falta de previsión o precaución del legislador sino más bien el fruto de las distintas circunstancias sociales, políticas y demográficas que rodearon a la legislación matrimonial del emperador. Bajo este contexto, Treggiari (1993, p. 60 ss.) define exactamente cuáles son los efectos jurídicos de esta legislación al decir que:

"Augustus introduced radical legislation which modified rights to marry, manipulated freedom to dispose of property, and attempted to encourage marriage and reproduction, especially in sections of society most susceptible to the type of rewards (praemia- and penalties poenae) which the emperor had at his disposal. Augustus laws responded to a complex situation and shifting political possibilities. They are themselves complex".

Por resumir, tanto la Lex Iulia de maritandis ordinibus como la Lex Papia Poppaea nuptialis forman un solo texto, fruto de la refundición de ambos, denominado Lex Iulia et Papia Poppaea (9 d.C.) cuya finalidad primordial es la de intentar la restauración de la familia romana sobre la base de las tradiciones y de los mores maiorum para desarrollar una política legislativa que favorezca las uniones matrimoniales lícitamente contraídas y la procreación. En su virtud todos los ingenuos, salvo los Senadores y sus descendientes, podían contraer matrimonio con los libertos y desaparece cualquier impedimento al matrimonio originado por la distinta clase o condición social. Sin embargo, se sancionaban determinadas prohibiciones matrimoniales de carácter social como luego enunciaremos.

Para entender el alcance y sentido jurídico de estas leyes, consideramos necesario detenernos tanto en sus orígenes como en los fundamentos que le dan su razón de ser durante el Principado de Augusto. De esta manera, estas ocupan un lugar preeminente dentro de la gran obra de reforma política y social de Augusto porque su finalidad principal era la regeneración de la población romana terminando con la procreación de la numerosa prole que había en la época. Durante su gobierno publicó multitud de leyes con estos objetivos, pero fracasó y tuvo que abandonar algunos de sus proyectos, salvo el triunfo de las ya mencionadas Lex Iulia de maritandis ordinibus y la Lex Iulia et Papia Poppaea que se configuran como las fuentes de mayor importancia para el Derecho Romano clásico. A modo de ejemplo, Del Castillo (1988) señala en su trabajo que, la unión de las dos leyes matrimoniales de Augusto fue tan perfecta, que pasaron a ser designadas en forma conjunta como una sola ley. De una y otra norma, pasamos a hablar a continuación:

augusteas, Sevilla (Editorial Secretariado de Publicaciones de la Universidad de Sevilla), 1987, p. 20. 
a) Lex Iulia de Maritandis Ordinibus: Hacemos referencia a aquella ley, rogada por Augusto y votada en el año 18 a.C., favorecedora de los matrimonios entre personas del mismo rango social y de la natalidad legítima ${ }^{5}$. A su vez, establecía cargas de tributación y restricciones de derecho hereditario para solteros (caelibes) y casados sin descendencia (orbi), al mismo tiempo que concedía ventajas económicas a los progenitores. Al igual

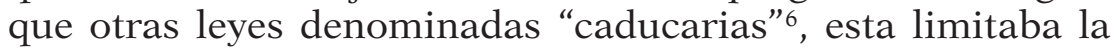
posibilidad de adquirir mortis causa al viudo sin hijos y a los solteros. Por ello, los bienes vacantes (bona caduca) pasaban a los herederos o padres legatarios y, en su defecto, iban a parar al Erario ${ }^{7}$.

b) Lex Iulia et Papia Poppaea: La importancia de esta ley concedida por Augusto deriva del hecho de que su vigencia perdura a lo largo de toda la etapa de mayor esplendor del Imperio Romano. En relación con su contenido ${ }^{8}$, podemos decir que favorecieron a las personas casadas o con hijos, así como restringieron los derechos hereditarios de solteros y casados sin descendencia9 . A tenor de lo anterior, podemos afirmar que el

5 Posteriormente, en el año 4 d.C., Augusto rogó otra ley de igual nombre que la anterior pero que introdujo modificaciones sustanciales.

6 En esta misma clasificación nos encontramos también con la Lex Papia Poppaea Nuptialis, votada en el año 9 d.C., que modifica la Lex Iulia.

7 Las fuentes que regulan esta cuestión con la intención de reformar las costumbres son, entre otras, Gai. 1,178: Nam et lege Iulia de maritandis ordinibus ei, quae in legitima tutela pupilli sit, permittitur dotis constituendae gratia a praetore urbano tutorem petere; D. 23,2,44 (Paul. 1 ad Leg. Iul. et Pap.): Lege Iulia ita cavetur: "QUI SENATOR EST, QUIVE FILIUS, NEPOSVE EX FILIO, PRONEPOSVE EX FILIO NATO CUIUS EORUM EST, ERIT, NE QUUIS EORUM SPONSAM UXOREMVE SCIENS DOLO MALO HABETO LIBERTINAM, AUT EAM, QUAE IPSA, CUIUSVE PATER MATERVE ARTEM LUDICRAM FACIT, FECERIT; NEVE SENATORIS FILIA, NEPTISVE EX FILIO, PRONEPTISVE EX NEPOTE FILIO NATO, NATA, LIBERTINO EIVE, QUI IPSE CUIUSVE PATER MATERVE ARTEM LUDICRAM FACIT, FECERIT, SPONSA NUPTAVE SCIENS DOLO MALO ESTO; NEVE QUIS EORUM DOLO MALO SCIENS SPONSAM UXOREMVE EAM HABETO; D. 30,96,1 (Iul. 39 dig.): Quoties lege Iulia bona vacantia ad fiscum pertinent, et legata, et fideicommissa praestantur, quae praestare cogeretur heres, a quo relicta erant; D. 38,11,1 (Ulp. 47 ad edictum): Vel secundum tabulas peti bonorum possessio potest; nihil enim capi propter iniustm matrimonium potest. Además, existen otros textos que de forma indirecta tratan esta cuestión, vid. Ulp. 11,20 [Ulp. Tit.], Ulp. 13,1 [Ulp. Tit.] y Coll. IV,2,1.

8 Para un análisis más detallado, vid. Ulp. 1,21,17 [Ulp. Tit.]; Ulp. 16,2 [Ulp. Tit.]; CJ. 6,51; CJ. 8,57,2; CJ. 5,5.

9 Entre las fuentes que tratan esta cuestión podemos citar Gai. 1,145: Itaque si quis filio filiaeque testamento totorem dederit, et ambo ad pubertatem pervenerint, filius quidem desinit habere tutorem, filia vero nihilo minus in tutela permanet: tantum enim ex lege Iulia et Papia Poppaea iure liberorum a tutela liberantur feminae;

(C) UNED. Revista de Derecho UNED, núm. 26, 2020 
interés fiscal hizo que se aplicaran celosamente y, de este modo, la restricción de la capacidad hereditaria que afectaba a los célibes y a aquellos casados sin hijos, producía la pérdida de ciertas proporciones hereditarias que, en numerosos casos, iban a parar al tesoro público ${ }^{10}$. El rigor de la ley empezó a ser templado con la concesión del ius liberorum, que el Senado y después el Príncipe concedía por razones especiales a personas que no se encontraban en las condiciones requeridas por la ley. Con la extensión de la ciudadanía romana a todos los súbditos libres del Imperio, decae el fin político de la ley, que era el de cierta defensa de la pureza de la raza latina y proveer a la población romana necesaria para el gobierno del Imperio. Así, la ley empieza a perder vigencia, también influenciada de la concepción cristiana del matrimonio, que no toleraba ninguna coacción para su realización y tampoco las rígidas prohibiciones matrimoniales. Por lo que, como concluye Falçao (1973, pp. 11-12), Justiniano acabó por abolirla.

Otro de los contenidos regulados en esta norma es el hecho de que, al igual que la anterior ley, estaban obligados a contraer matrimonio los cives comprendidos entre los veinticinco y los sesenta años, así como las romanas mayores de veinte y menores de cincuenta. Sin embargo, esta norma además exigía la procreación y determinaba el número de hijos según los casos por lo que a los matrimonios de ingenuos se les obligaba a tener tres y a los libertos cuatro. En lo que se refiere a las viudas o divorciadas, estas debían contraer nuevo matrimonio en el plazo máximo de seis meses a dos años, excepto que hubiesen tenido ya tres hijos legítimos o cuatro, si

Gai. 2,206-208: Post legem vero Papiam deficientis portio caduca fit et ad eos pertinet, qui in eo testamento liberos habent; D. 23,2,11 (Iul. 62 dig.): Si filius eius, qui apud hostes est, vel absit, ante triennium captivitatis vel absentiae patris uxorem duxit, vel nupcias contrahi; D. 23,2,44 (Paul 1 ad Leg. Iul. et Pap.): Lege Iulia ita cavetur: "QUI SENATOR EST, QUIVE FILIUS, NEPOSVE EX FILIO, PRONEPOSVE EX FILIO NATO CUIUS EORUM EST, ERIT, NE QUUIS EORUM SPONSAM UXOREMVE SCIENS DOLO MALO HABETO LIBERTINAM, AUT EAM, QUAE IPSA, CUIUSVE PATER MATERVE ARTEM LUDICRAM FACIT, FECERIT; D. 23,2,45,5 (Ulp. 3 ad Leg. Iul. et Pap.): Deinde ait lex: "invito patrono»; invitum accipere debemus eum, qui non consentit ad divortium; idcirco nec a furioso divertendo solvit se huius legis necessitate, nec si ab ignorate divorterit; rectius enim hic invitus dicitur, quam qui dissensit; D. 24,3,64,6 (Ulp. 7 ad Leg. Iul. et Pap.): Quod ait lex: QUANTA PECUNIA ERIT, TANTAM PECUNIAM DATO, ostendit, aestimationem hereditatis vel bonorum liberti, non ipsam hereditatem voluisse legem praestare, nisi maritus ipsas res tradere maluerit; et hoc enim benignius admitti debet.

10 D’ORS, A., Derecho Privado Romano, Pamplona (Editorial Servicio de Publicaciones de la Universidad de Navarra), 1977, p. 273-274. 
estos eran libertos ${ }^{11}$. A modo de resumen, podemos decir que las leyes matrimoniales promulgadas durante el Principado favorecieron los matrimonios ampliando el círculo de personas que entre ellas tenían conubium, aunque se distinguiesen claramente las clases sociales y su regulación jurídica. La finalidad principal de estas normas fue, en suma, el tratar de evitar el matrimonio entre personas desiguales y, a su vez, preservar el rango senatorial. Además, las Leyes augusteas $^{12}$ impusieron determinadas limitaciones al divorcio, como la prohibición de que la liberta se divorciase unilateralmente contra la voluntad de su patrono-marido y, también, el establecimiento de una determinada forma para realizar el repudium.

\section{DEROGACIÓN PARCIAL DE LAS LEYES MATRIMONIALES CON EL EMPERADOR CONTANTINO I}

Si bien la Lex Iulia de maritandis ordinibus y la Lex Papia Poppaea habían introducido interesantes innovaciones para el Derecho clásico y se configuraron como un imperativo matrimonial, a partir del siglo IV d.C. empiezan a caer en desuso debido al desplazamiento del centro de gravedad del Imperio hacia Oriente y la oposición del Cristianismo con sus ideas nuevas acerca del matrimonio, quedando en el Derecho justinianeo algunos restos insignificantes de ellas. A pesar de que fue el emperador Justiniano ${ }^{13}$ quien derogó expresamente la legislación matrimonial de Augusto, ya el 31 de

11 Para las mujeres, este precepto fue un cambio respecto a lo que había venido siendo la tradición porque dejaban de tener la consideración social de univiriae. Sobre esta cuestión, vid. Ulp. 14 y 16 (Ulp. Tit.); Fest., 242, b,30; Propert., 5,11,36 (68); Virg. Aen., 4, 28-29; Liv., 10,23; Val. Max., 2,1,3; Tac., Ann., 2,86; Plut., Quaest. Rom., 105 y epitafios C. I.L., II, 78; III, 3572; V, 7763; VI, 2318, 3604, 13 299, 13 303; VIII, 7384, 7537; IX, 3158; X, 3058, 3351; XI, 1800, 2538; XIV, 418-19 y 839).

12 De una y otra, pasamos a ver su regulación en textos como D. 24,2,9 (Paul. 2 de adulteriis): Nullum divortium ratum est, nisi septem civibus Romanis puberibus adhibitis praeter libertum eius, qui divortium faciet. Libertum accipiemus etiam eum, qui a patre, avo, proavo, et ceteris susum versum manumimissus sit; D. 24,2,11 (Ulp. 3 ad Leg. Iul. et Pap.): Quod ait lex: DIVORTII FACIENDI POTESTAS LIBERTAE, QUAE NUPTA EST PATRONO, NE ESTO, non infectum videtur effecisse divortium, quod iure civili dissolvere solet matrimonium; quare constare matrimonium dicere non possumus, quum sit separatum; D. 38,11,1,1 (Ulp. 47 ad edictum): Ut autem haec bonorum possessio locum habeat, uxorem esse portet mortis tempore; sed si divortium quidem secutum sit, veruntamen iure durat matrimonium, haec successio locum non habet. Hoc autem in huiusmodi speciebus proceditt: liberta ab invito patrono divortit; lex Iulia de maritandis ordinibus retinet istam in matrimonio, dum eam prohibet alii nubere invito patrono; item Iulia de adulteriis, nisi certo modo divortium factum sit, pro infecto habet.

13 CJ. 6,51,1 del 534 d.C.

(C) UNED. Revista de Derecho UNED, núm. 26, 2020 
enero del año 320 d.C. el emperador Constantino I había suprimido parcialmente el contenido de estas leyes a través de una Constitución dirigida ad populum, de cuya cita se puede extraer literalmente que:

Qui iure veteri caelibes habebantur, inminentibus legum terroribus liberentur adque ita vivant, ac si numero maritorum matrimonii foedere fulcirentur, sitque omnibus aequa condicio capessendi quod quisque mereatur. Nec vero quisquam orbus habeatur: proposita huic nomini damna orbus habeatur: proposita huic nomini damna non noceant. Quam rem et circa feminas aestimamus earumque cervicibus inposita iuris imperia velut quaedam iuga solvimus promiscue omnibus. Verum huius beneficii maritis et uxoribus inter se usurpatio non patebit, quorum fallaces plerumque blanditiae vix etiam opposito iuris rigore cohibentur, sed maneat inter istas personas legum prisca auctoritas (C. 8,16,1).

La aportación esencial de esta Constitución es que con ella se derogan las limitaciones hereditarias de herederos ajenos, se promueve el principio de libertad de la mujer tanto para no contraer matrimonio contra su voluntad, como para permanecer viuda. Además, se mantiene la incapacidad de recibir inter virum et uxorem que definitivamente fue suprimida posteriormente por el emperador cristiano Teodosio II, en el año 410 d.C. ${ }^{14}$. En este contexto, Constantino $\mathrm{I}^{15}$ fue emperador romano durante los años 306-337 d.C., y fundó la ciudad de Constantinopla. Constantino unificó un Imperio tambaleante, reorganizó el Estado romano y preparó el terreno para la victoria final del Cristianismo a finales del siglo IV d.C. Así, resultan muy significativas las palabras de Bonfante (1929, p. 257) quien ini-

14 CTh. 8,17,2 del año 410 d.C.

15 Nacido en Naissus con el nombre de Flavio Valerio Constantino, luchó contra los sármatas y se unió a su padre en Britania, en el 306. Fue tan popular entre sus tropas que le proclamaron augusto cuando Constancio murió ese mismo año. Sin embargo, durante las dos siguientes décadas tuvo que luchar contra sus rivales al trono, y no logró ser emperador único hasta el 324. Siguiendo el ejemplo de su padre y de los anteriores emperadores del siglo III, en su juventud fue un henoteísta solar. Consideraba que el dios romano Sol era la manifestación visible de un Dios Supremo invisible (summus deus), que era el principio del Universo, y que era equiparado con el emperador romano. Intervino en los asuntos eclesiásticos procurando establecer la unidad de la Iglesia, amenazada por el arrianismo; con este fin presidió el primer Concilio ecuménico de la Iglesia en Nicea, en el 325. También comenzó la construcción de Constantinopla, en el 326, en el emplazamiento del antiguo Bizancio griego. La ciudad se terminó en el 330 (ampliada más tarde), y fue embellecida con antiguas obras de arte griego. Además, Constantino construyó iglesias en Tierra Santa, donde se supone que Elena, su madre, encontró la Vera Cruz en la que se crucificó a Jesús. El emperador fue bautizado poco antes de su muerte, el 22 de mayo del 337. (Sobre Constantino, vid. BONFANTE P. Instituciones de Derecho Romano, Madrid, 1929, p. 250 ss.) 
cia sus estudios sobre la legislación de Constantino empleando adjetivos calificativos, como legislación "enérgica" y "violenta", tal y como se desprende literalmente de sus palabras: "Energica, anzi violenta ad eccesiva, come tutta la sua legislazione fu la prima reazione al divorzio di Constantino".

En este punto, nos preguntamos cuáles fueron los motivos que llevaron a Constantino I a redactar la Constitución y, por ende, por qué quería el emperador suprimir parcialmente la legislación matrimonial de Augusto. Sobre este particular, se han pronunciado algunos autores que, desde sus diferentes posturas acerca de la influencia cristiana de la Constitución, sostienen que: a) Autores contrarios a la influencia del Cristianismo en la Constitución del emperador Constantino I: Se suele admitir que a este grupo pertenecen autores como Piganiol, de actitud contraria a la política de Constantino, quien considera que la influencia de la filosofía pagana es la verdadera causa de esta Constitución. b) Autores que sostienen la influencia del Cristianismo en la Constitución de Constantino I: Es opinión admitida, que en esta Constitución hay una notable influencia cristiana. Los motivos que llevan a la Iglesia a derogarla son: en primer término, contrariaba el sentido cristiano de la virginidad y el estado de viudedad. Además, la totalidad de los clérigos o bien eran caelibes o futuros orbi porque no podían contraer matrimonio y, desde el punto de vista patrimonial, también perjudicaba a la Iglesia porque ni las iglesias locales no podían ser instituidas herederas por ser personae incertae ni tampoco los clérigos por su incapacidad pasiva.

Pero cuáles son los verdaderos argumentos que llevan al autor a afirmar la influencia eclesiástica en el texto de Constantino. En este sentido, resulta significativo el hecho de que esta Constitución coincida cronológicamente con otras medidas que favorecen a la Iglesia Católica, como son: la capacidad sucesoria de las iglesias ${ }^{16}$, la episcopalis audientia ${ }^{17}$, la manumissio in ecclesia ${ }^{18}$, etc. Asimismo, Constantino se ve influenciado por su íntimo amigo, el obispo español Osio de Córdoba, quien trabajó en la Corte del emperador entre el año 312 y 325 d.C. e influyó no sólo en su conversión sino también en la expansión del Cristianismo. Por último, no podemos olvidarnos de la calificación que hace Eusebio de Cesarea $^{19}$ en su obra al

16 C. 16,2,4 del año 321 d.C. en relación con CJ. 1,12,1.

17 C. $1,27,1$ del año 318 d.C.

18 C. 4,7,1 del año 321 d.C. en relacion con CJ. 1,13,2.

19 EUSEBIO, Vita Constantini 4, p. 26-28. en DOMINGO, R., La Legislación Matrimonial de Constantino, Pamplona (Editorial Universidad de Navarra), 1989, p. 31.

() UNED. Revista de Derecho UNED, núm. 26, 2020 
mantener que la Constitución era santa y religiosa, o aquella otra opinión de San Ambrosio ${ }^{20}$ quien todavía recuerda las leyes caducarias de Augusto en su Liber de viduis.

En suma, podemos sostener que la importancia de la figura del emperador Constantino I está en la derogación parcial que hace de las leyes matrimoniales de Augusto, puesto que ello contribuyó decisivamente a la expansión de la Iglesia Católica y a la importancia del Cristianismo como religión. A lo anterior se añade un hecho indispensable en la época clásica como es la sustitución de la poena caelibatus por la poena secundarum nuptiarum, demostrándose la hostilidad hacia las segundas nupcias ${ }^{21}$. En relación con la cuestión de las circunstancias limitativas a contraer matrimonio, el emperador Constantino utiliza la palabra "prohibición" para referirse a la imposibilidad de que ciertas personas contrajeran justas nupcias. En especial, mantuvo las prohibiciones clásicas, pero aumentó aquellas de carácter social a través de una Constitución del año 336 d.C., que literalmente dice así:

Senatores seu perfectissimos, vel quos in civitatibus duumviralitas vel quinquennalitas vel fla(monii) vel sacerdotii provinciae ornamenta condecorant, placet maculam subire infamiae et peregrinos a Romanis legibus fieri, si ex ancilla vel ancillae filia vel liberta vel libertae filia, sive Romana facta seu Latina, vel scaenica vel scaenica filia, vel ex tabernaria vel ex tabernari filia vel humili vel abiecta vel lenonis vel harenarii filia vel quae mercimoniis publicis praefuit, susceptos filios in numero legitimorum habere voluerint aut proprio indicio aut nostri praerogativa rescribti, ita ut, quidquid talibus liberis pater donverit, sive illos legitimos seu naturales dixerit, totum retractum legitimae suboli reddatur aut fratri aut sorori aut patri aut matri (C. 4,6,3).

Con esta Constitución, en definitiva, el emperador amplía la prohibición clásica que tenían los Senadores de casarse con una mujer liberta o de humilde nacimiento a otros altos cargos, como los perfectissimi, los duoviri municipales, los sacerdotes provinciales, etc. Además, determina a qué mujeres afectan tales prohibiciones, aunque la expresión utilizada por el texto, humili vel abiecta, resulta de difícil interpretación ${ }^{22}$. Si bien entendemos que humilis se refiere a

20 S. AMBROSIO, De viduis 14, p. 84-85 (PL. 16, 274) en DOMINGO, R., La Legislación Matrimonial de Constantino, cit., p. 32.

21 Ello ha quedado reflejado en dos Constituciones: C. 3,30,3,5 del año 326 d.C. (en relación con CJ. 5,37,22,5); C. 8,18,3 del 334 d.C.

22 Sobre este particular existen opiniones dispares como las de Cardascia y De Robertis, por una parte, y M. Falçao y R. Domingo, por otra. Apoyamos la tesis de estos dos últimos juristas quienes afirman que dicha Constitución hace referencia a las mismas prohibiciones matrimoniales de la época clásica que afectaban a las uniones entre una mujer con los miembros de la clase senatorial. De 
la mujer de baja condición social por ser de humilde nacimiento, y abiecta alude a la mujer de vida indecorosa e impúdica. Por último, algunos autores entienden que fue Constantino el emperador que incluyó el rapto dentro de la clasificación de prohibiciones a contraer justas nupcias ${ }^{23}$; sin embargo, esto no fue obra de este emperador sino de Justiniano tal y como se deriva del análisis de las fuentes con las que contamos ${ }^{24}$. Comprendemos, pues, que el error que cometen estos juristas se fundamenta en el hecho de entender que el crimen cometido entre un raptor y su raptada es un obstáculo al matrimonio cuando, en realidad, se trata de un delito sancionado con severas penas para el raptor o aquellas otras personas involucradas, esto es, los padres de la raptada, los instigadores, etc. La Constitución que recoge este hecho es del año 320 d.C., y dice así:

Et quoniam parentum saepe custodiae nutricum fabulis et pravis suasionibus deluduntur, his primum, quarum detestabile ministerium fuisse arguitur redemptique discursus, poena immineat, ut eis meatus oris et faucium, qui nefaria hortamenta protulerit, liquentis plumbi ingestione claudatur (C. 9,24,1).

\section{HACIA UNA CLASIFICACIÓN DE LOS MATRIMONIOS ROMANOS ILEGALES INEXISTENTES O NULOS}

Como ya tuvimos ocasión de apuntar ${ }^{25}$, la importancia del consentimiento como requisito constitutivo del matrimonio romano deriva de la necesidad de que esa voluntas manifestada externamente fuese auténtica y que dicho consentimiento no esté viciado o haya error. En realidad, se puede afirmar que el Derecho clásico no trataba de descubrir la intención de los cónyuges a la hora de contraer el vínculo matrimonial, sino más bien se limitaba a exigir una voluntad jurídica, consciente y verdadera, de querer formar un matrimonium iustum con ius conubii. Por este motivo, en Roma aparecen distintas clases de uniones en función de los requisitos que las conforman; la particularidad que presenta cada una de ellas es que

este modo, se les impedía el matrimonio a la esclava, la liberta, a la mujer ingenua de condición humilde por su nacimiento o humilis (obscuro loco nata), y a la mujer de vida deshonesta o abiecta denominada también turpis. (DOMINGO, R., La Legislación Matrimonial de Constantino, cit., p. 34-36.).

J. Iglesias.

${ }_{23}$ Nos referimos, entre otros juristas ilustres, a E. Volterra, P. Bonfante, y

24 Entre otras, vid. CJ. 9,13,1,2 del año 533 d.C.; Nov. J. 143 y Nov. J. 150.

25 MUÑOZ CATALÁN, E., "Consentimiento viciado o error en los matrimonios de conveniencia celebrados desde la antigua Roma”, RJUA: Revista Jurídica de la Universidad Autónoma de Madrid, 27, 2013 [En línea]: http://www. uam.es/otros/rjuam/numeros_publicados.html 
carecen de los requisitos y elementos esenciales como para considerar a estas uniones un matrimonio contraído conforme al Derecho clásico y, en consecuencia, forman parte de la clasificación de iniustum por su ausencia de conubium (de forma directa o indirecta) y de affectio maritalis.

Tanto Á. D’Ors como Volterra han tratado de resumir la esencia de estos tipos de matrimonium iniustum. En este sentido, Á. D`Ors (1977, p. 282) afirma que el derecho a contraer un matrimonio legítimo se llama conubium, y sólo lo tienen los ciudadanos romanos y algunos extranjeros privilegiados. Por lo que la unión conyugal de los que no tienen conubium, no produce efectos jurídicos y se considera como un matrimonium iniustum pero no nulo, pues de nulidad no se puede hablar propiamente porque el matrimonio romano no es considerado como un acto jurídico sino como una situación de hecho. Por su parte, Volterra (1972, p. 469) al tratar este tipo de matrimonios sostiene que el conubium es un requisito positivo consistente en la capacidad jurídica y recíproca de constituir entre ellos una relación conyugal válida. A la hora de exponerlos, hemos preferido diferenciar entre los matrimonios iniustum inexistentes y los nulos o ineficaces porque presentan supuestos distintos ${ }^{26}$. Lo cierto es que en las fuentes no existe una diferenciación clara entre ambas clases de matrimonios injustos y debemos acudir a la consideración del vínculo conyugal como un hecho social con relevancia jurídica y no meramente una res facti.

\section{A. Matrimonium iniustum inexistente o non potest}

Esta variedad de vínculo marital deriva de los supuestos en los que, además de no existir ius conubii entre los contrayentes, tampoco había consentimiento mutuo entre estos o este no era exteriorizado de forma auténtica. Al hablar de matrimonio iniustum no potest se hace referencia a aquellas uniones conyugales inexistentes o en defecto del consensus por lo que, en este sentido, el elemento subjetivo se configura como un requisito positivo necesario para ser considerado como matrimonium iustum. Así, la affectio se manifiesta en el asentimiento consciente prestado por quienes jurídica-

26 Para un estudio inicial de la materia, vid. MUÑOZ CATALÁN, E., "Las uniones extramatrimoniales ante la falta de conubium: Fundamento jurídico de los impedimentos matrimoniales en la Roma clásica", en Arias Montano: Repositorio institucional de la Universidad de Huelva. 2013. Colección de Tesis Doctorales, pp. 338-736 [En línea]: http://rabida.uhu.es/dspace/bitstream/handle/10272/6457/Las_ uniones_extrama trimoniales.pdf? sequence $=2$ 
mente están facultados para ello, esto es, el vir y la uxor que tienen la consideración de cives. Los cuales, pasamos a describir a continuación:

a) Matrimonio del demente: Hacemos referencia al vínculo contraído por aquella persona que ha sido privada de juicio en razón de su situación mental y, como consecuencia, se ve afectada por una incapacidad de obrar absoluta. En este sentido, las fuentes sostienen que el furious ${ }^{27}$ (o también denominado demens o mente captus) ha contraído un matrimonio que para el Derecho es inexistente en razón de su incapacidad, pero nunca utilizan el término "inexistente" sino que hacen uso de palabras como contrahere o ducere non potest. Asimismo, cabe señalar que la escasez de fuentes ${ }^{28}$ que tratan esta cuestión dificulta la determinación de aquellos supuestos en los que estamos ante anomalías mentales ${ }^{29}$, y las fuentes que existen

27 Sobre el furiosus, vid. D. 1,18,14 (Macer 5 de iudic. public. divas Mar. et Com. scapul. tertu.) y D. 29,7,2,3 (Iul. 37 dig.).

28 En lo que se refiere a las fuentes que regulan la materia directamente o de forma total podemos señalar las siguientes: PS. 2,19,7: Neque furiosus neque furiosa matrimonium contrahere possunt: sed contractum matrimonium furore non tollitur; D. 23,2,16,2 (Paul. 35 ad edictum): Furor contrahi matrimonium non sinit, quia consensu opues est; sed recte contractum non impedit; D. 1,6,8 (Ulp. 9 ad sabinum): Nam furiosus, licet uxorem ducere non possit; D. 23,2,38 (Paul. 2 sententiarum): Si quis officium in aliqua provincia administrat, inde oriundam vel ibi domicilium cum furiosa non fuit; D. 3,2,11,1 (Ulp. 6 ad edictum): Etsi talis sit maritus, quem mos maiorum lugeri non oportet, non posse eam nuptum intra legitimum tempus collocari; D. 36,1,79,1 (Scaev. 20 dig.): Nam etsi matrimonium cum furiosa non fuit. Sin embargo, existen otras fuentes que regulan la materia indirectamente o de forma parcial como D. 24,1,3,1 (Ulp. 32 ad sabinum): Sed si aliquod impedimentum interveniat me sit omnino matrimonium, donatio valebit; ergo si senatoris filia libertino contra senatus consultum nupserit, vel provincialis mulier ei, qui ibi meret, contra mandata, valebit donatio, quia nuptiae non sunt; D. 23,2,63 (Pap. 1 definitionum): Praefectus cohortis vel equitum, aut tribunus contra interdictum eius provinciae duxit uxorem, in qua officium gerebat; matrimonium non erit; quae species pupillae comparanda est, quum ratio potentatus nuptias prohibuerit. Sed an huic quoque si virgo nupsit, non sit auferendum, quod testamento relictum est, deliberari potest. Exemplo tamen pupillae nuptae tutori, quod relictum est, potest mulier consequi, pecuniam tamen in dotem datam mulieris heredi restitui necesse est. Asimismo, señalamos determinadas fuentes que usan el término "impedimento" y/o "meros obstáculos" para los supuestos de "inexistencia" como D. 23,2,16 [Paul. 35 ad edictum]: Orationi Divi Marci cavetur, ut, si senatoris filia libertino nupsisset, nec nuptiae essent: quam et senatus consultum secutum est; D. 23,2,42,1 [Mod. libr. sing. de rit. nup.]) y D. 23,2,66 (Paul. 2 sententiarum).

29 La profesora Núñez Paz nos advierte en su obra que a la falta de claridad sobre esta cuestión se añade el hecho de que se haya perdido la página de las Instituciones de Gayo que trata esta cuestión. Sólo nos queda analizar algunas obras de autores de la talla de Audivert y Nardi (NÚÑ̃Z PAZ M. I., Consentimiento matrimonial y divorcio en Roma, cit., 1988, p. 38).

(C) UNED. Revista de Derecho UNED, núm. 26, 2020 
tampoco aclaran qué grado de demencia debía tener el cónyuge como para ser considerado como tal, por lo que nosotros entendemos que debía tratarse de una persona absolutamente incapaz. En cualquier caso, hay que tener presente que en el supuesto de que a uno de los cónyuges, hombre (furiosus) o mujer (furiosa), le hubiese sobrevenido una enajenación mental ello no invalidaría el matrimonio y este continuaba siempre que la otra parte conservase la intención de estar unido en matrimonio ${ }^{30}$. Así resume Robleda (1970) a este tipo de matrimonios al señalar en su trabajo la necesaria relación entre el Derecho y las facultades espirituales del hombre pues donde el hombre, como tal, no actúa no se puede hablar de derecho respecto de él ni como sujeto activo ni como sujeto pasivo.

b) Matrimonio simulado: Se trata del segundo supuesto de inexistencia jurídica de matrimonium a pesar de que las fuentes directamente tampoco emplean el vocablo "inexistencia". El término simulare se traduce por simular, imitar o llevar a cabo aparentemente un acto o negocio jurídico, que aplicado al matrimonium romano es entendido como un hecho con relevancia social por lo que se trata de la discordancia entre las voluntades declaradas y las que verdaderamente son queridas. En este contexto, cabe resaltar la frase contenida en D. 23,2,30 (Gai. 2 legem iuliam et papaiam) al señalar que simulate nuptiae nullius momenti sunt. El problema doctrinal se plantea a la hora de determinar el alcance de la expresión nullius momenti sunt, puesto que se podría estar limitando el texto jurídico así como sus efectos. En este sentido entendemos que, en la medida en la que el consentimiento es el elemento esencial del matrimonio romano, su ausencia no lleva aparejada la nulidad del vínculo marital sino su inexistencia jurídica que se refleja en los efectos que debiera producir de haberse presatado un consentimiento no sólo inicial, sino también continuado y, como consecuencia, el matrimonio simulado no tiene ningún valor jurídico. Así, no cabe hablar de nulidad, ineficacia o matrimonio inoperante (quia prius est esse quam operari) sino de inexistencia jurídica en cuanto que falta la affectio maritalis entre los cónyuges que han contraído un vínculo simulado. Lo que sí

30 Sobre este particular debemos tener en cuenta D. 23,2,16,2 (Paul. 35 ad edictum): Furor contrahi matrimonium non sinit, quia consensu opus est; sed recte contractum non impedit; D. 23,1,8 (Gai. 11 ad edictum provinciale): Furor quin sponsalibus impedimento sit, plus quam manifestum est, sed postea interveniens sponsalia non infirmat; PS. 2,19,2: Eorum, qui in potestae patris sunt, sine voluntate eius matrimonia iure non contrahuntur, sed contracta non solvuntur. 
podrían, de interesarles continuar con un matrimonio simulado, es estar unidos en matrimonio siempre que exteriorizasen su voluntad jurídica de estar unidos y se demostrasen mutuamente el honor matrimonii.

c) Matrimonio por miedo: Aludimos a aquel matrimonium contraído contra la voluntad de, al menos, uno de los cónyuges. El miedo efectivamente no impide que existiese consentimiento mutuo y, por ello, hubo matrimonio aunque fuese contraído bajo presión y sin existir una voluntad expresada libremente entre los contrayentes o lo que se conoce en las fuentes como maluisse videtur ${ }^{31}$. Estos matrimonios han sido también objeto de debate por considerarse tanto ineficaces como inexistentes. Nosotros los englobamos dentro de los iniustum matrimonium $\mathrm{y}$, a su vez, en el subgrupo de los inexistentes al faltar el elemento del consensus. Las principales fuentes ${ }^{32}$ que tratan la cuestión del metus lo reflejan al no considerar que pudiese existir la nulidad del vínculo por ineficacia.

Se desprende, en consecuencia, que el matrimonio contraído por miedo no fue válido para el Derecho postclásico y por tanto se considera como "no contraído" debido al cambio en la concepción del consensus como inicial. Sin embargo, la doctrina tiene tesis contrapuestas en cuanto a la fundamentación y sentido de esta clase de matrimonio en Derecho clásico. La diversidad de opiniones doctrinales que interpretan estas fuentes nos hacen reparar entre las más autorizadas, por ejemplo, a lo largo de su trabajo Orestano (1940) sostiene que matrimonio y coacción son términos que no pueden ir unidos; entiende que el matrimonio realizado con miedo era válido durante la etapa clásica debido a la concepción del matrimonio basado en un consentimiento continuado y no meramente inicial. Así, a lo largo del tiempo que duraba el vínculo conyugal podría existir momentos de participación voluntaria de la parte que había sido coartada o amenazada con miedo o violencia, mostrando libremente su consensus. En la misma línea, Robleda (1970, p. 135) mantiene que el matrimonio de aquella persona que ha sido coaccionada

31 Sobre este particular, vid. D. 23,2,22 (Cel. 15 dig.) y D. 4,2,21,5 (Paul. $11 \mathrm{ad}$ edictum).

${ }^{32}$ Así se establece en D. 23,2,21 (Terenc. 13 ad Leg. Iul. et Pap.): Non cogitur filiusfamilias uxorem ducere; CJ. 5,4,14: Neque ab initio matrimonium contrahere neque dissociatum reconciliare quisquam cogi potest; D. 23,2,22 (Cel. 15 dig.): Si patre cogente ducit uxorem, quam non duceret, si sui arbitrio esset, contraxit tamen matrimonium, quod inter invitos non contrahitur, maluisse hoc videtur; D. 4,2,21,5 (Paul. 11 ad edictum): Si metu coactus adii hereditatem, puto me heredem effici, quia quamvis si liberum esset noluissem, tamen coactus volui.

(C) UNED. Revista de Derecho UNED, núm. 26, 2020 
es completamente válido pues ante el miedo caben dos reacciones: el sujeto puede ceder y contraer matrimonio (al no anularle su consentimiento el miedo) o, por el contrario, resistir la coacción moral para no contraer matrimonio ya que, en caso contrario, sería realizado de forma involuntaria o contra su voluntad (invitus).

La diferencia con el autor anterior es que, este último, entiende que se trata de un consentimiento inicial el que se otorgaba en la época clásica. En particular mantiene que el matrimonio contraído por miedo en la etapa clásica fue siempre válido, en base a la consideración de una voluntad para contraer matrimonium de carácter ético-social y no meramente jurídica. No obstante, la situación cambia en el Derecho postclásico y el matrimonio contraído de forma coaccionada se considera como no celebrado al tratarse ya de una voluntad inicial suficiente para contrare iustum matrimonium. A tenor de lo anterior y, teniendo en cuenta las opiniones precedentes, podemos resumir que este tipo de matrimonios, además de celebrados en ausencia de conubium, derivan de un vicio del consentimiento y, por ello, son inexistentes. Además, lo que se tiene en cuenta es la voluntad formal o jurídica exteriorizada en cualquiera de las dos etapas analizadas, a pesar de que en el Derecho clásico sea más difícil que el consentimiento fuese continuado porque esta voluntad podía despararecer durante el tiempo que durase el vínculo.

\section{B. Matrimonium iniustum nullum}

Pertenecen a este grupo aquellos vínculos conyugales contraídos en ausencia de determinadas notas esenciales, como es el caso del conubium, que hacen que el matrimonio se considere nulo y que, en consecuencia, no produzca efectos jurídicos. El adjetivo latino nullus denota un sentido peyorativo a la hora de calificar a la unión contraída entre dos personas, por lo que el problema se plantea a la hora de delimitar el alcance y reconocimiento que les hace el Derecho Romano postclásico a este tipo de uniones. Centrándonos en esta clasificación, podemos afirmar que se trata de aquellos matrimonios ineficaces que el jurista Paulo ${ }^{33}$ denomina como matrimonio contractum, si bien, no iure. El motivo deriva del hecho de que la nulidad sea un defecto propio de los negocios jurídicos, los cuales, no producen el alcance deseado debido al vicio del que adolece. En tal sentido, nulo para los Romanos era aquel celebrado en contra-

33 PS. $2,19,2$. 
vención de las prescripciones del derecho positivo, concretadas en la exigencia de una determinada forma, la cual es sabido que era necesaria para una cierta clase de personas.

Por su parte, Falçao (1973, p. 26 ss.) aporta una visión más subjetiva de este tipo de matrimonios. Parte del hecho de que el matrimonio romano clásico era una situación de hecho con relevancia para el Derecho en el sentido de que, constituido válidamente, producía determinados efectos jurídicos. En este punto interpreta que el concepto de matrimonio nulo no existe en la etapa clásica porque se trata de un hecho con relevancia social pero sí cabe hablar de ineficaz, en cuanto que no ha cumplido con los requisitos exigidos. Bajo estas premisas, sostenemos que si bien no se puede hablar de nulidad propiamente dicha porque el matrimonio romano no era un acto con relevancia para el Derecho (como pudiera serlo cualquier negocio jurídico, por ejemplo) si podemos afirmar que existieron en Roma determinados matrimonium iniustum ineficaces para el Derecho Romano por no cumplir con las notas propias del matrimonium clásico. Así, la nulidad se refiere al estado del matrimonio que, en un determinado momento, no produce efectos y se considera ineficaz. Dentro de esta clasificación, nos encontramos con:

a) Matrimonio informe: Mientras que el Derecho Romano de la etapa arcaica exigía ciertas solemnidades para contraer matrimonium, el matrimonio clásico se caracterizaba por estar libre de forma, es decir, al ser un hecho con relevancia social lo que le importaba al Derecho es que este cumpliese con ciertos requisitos (capacidad jurídica y física de los contrayentes, respeto al Principio monogámico y consentimiento mutuo manifestado externamente a través del honor matrimonii). El término latino forma hace referencia a un requisito de validez del negocio o acto celebrado ${ }^{34}$. Nos referimos a una forma ad solemni-

34 Los textos jurídicos principales que recogen esta cuestión son D. 23,2,2 (Paul. 35 ad edictum): Nuptiae consistere non possunt, nisi consentiant omnes, id est, qui coëunt, quorumque in potestate sunt; D. 23,2,5 (Pomp. 4 ad sabinum): Mulierem absenti per literas eius, vel per nuntium posse nubere placet, si in domum eius deduceretur; eam vero, quae abesset; D. 23,2,6 (Ulp. 35 ad sabinum): Denique Cinna scribit: eum, qui absentem accepit uxorem, deinde rediens a coena iuxta Tiberim periisset, ab uxore lugendum, responsum est; D. 23,2,18 (Iul. 16 dig.): Nuptiae inter easdem personas nisi volentibus parentibus renovatae iustae non habentur; D. 23,2,21 (Terenc. 3 ad Leg. Iul. et Pap.): Non cogitur filiusfamilias uxorem ducere; D. 23,2,25 (Mod. 2 reg.): Filius emancipatus etiam sine consenso patris uxorem ducere potest, et susceptus filius ei heres erit; D. 23,2,30 (Gai. 2 ad Leg. Iul. et Pap.):Simulate nuptiae nullius momenti sunt; D. 23,2,22 (Cel. 15 dig.): Si patre cogente ducit uxorem, quam non duceret, si sui arbitrio esset, contraxit tamen matrimonium, quod inter invitos

(C) UNED. Revista de Derecho UNED, núm. 26, 2020 
tatem que debía cumplir todo matrimonio contraído válidamente y, si no se cumplían tales notas formales, se producía lo que conocemos como un matrimonio informe o infomis. Es en este punto donde nos preguntamos qué alcance tiene la forma durante la etapa clásica. Entendemos que la forma jurídicomatrimonial a la que nos referimos alude a la necesidad de que la affectio maritalis estuviese reconocida socialmente y se configurase como una iuris conditio para que el matrimonio clásico fuese eficaz desde el punto de vista jurídico. La ausencia de estas notas esenciales hacen que estemos ante un "matrimonio informe", o sea, iniustum, inexistente, ilegítimo, nulo y, en definitiva, contrario al Derecho clásico, por lo que no es firme y carece, en consecuencia, de efectos jurídicos.

b) Matrimonio contra mandata: Nos referimos a aquel matrimonio ineficaz por haber sido contraído contra una determinada orden o encargo. Si nos paramos a analizar las fuentes ${ }^{35}$ que tratan esta cuestión, observaremos que se emplean expresiones como nuptiae non sunt o matrimonium non est, y uno de los efectos principales es que los hijos nacidos de tales vínculos no son legítimos. En un primer momento, podrían parecen inexistentes y no meramente ineficaces o nulos. Sin embargo, la sanción que se impone a este tipo de matrimonium iniustum no es tan excesiva como para llegar a la inexistencia ${ }^{36}$.

c) Matrimonio de cives con peregrina carente de la civitas o con libertas: En este supuesto, también encontramos un tipo de matrimonio ineficaz pero existente para el Derecho Romano.

non contrahitur, maluisse hoc videtur; D. 23,2,35 (Pap. 6 resp.): Filiusfamilias miles matrimonium sine patris voluntate non contrahit

${ }_{35}$ Sobre esta cuestión, vid. D. 23,2,12 (Ulp. 26 ad sabinum) y D. 23,2,43 (Ulp. 1 ad Leg. Iul. et Pap.).

36 Para demostrar esta tesis creemos conveniente aportar los textos que tratan esta cuestión por recoger la idea de iustae nuptiae efficiuntur. Los textos son D. 23,2,38 (Paul. 2 sententiarum): Ergo si senatoris filia libertino contra senatus consultum nupserit, vel provincialis mulier ei, qui ini meret, contra mandata, valebit donatio, quia nuptiae non sunt; D. 23,2,63 (Pap. 1 definitionum): Si quis officium in aliqua provincia administrat, inde oriundam, vel ibi domicilium habentem uxorem ducere non potest, praefectus cohortes vel equitum aut tribunus contra interdictum eius provinciae duxit uxorem, in qua ifficium gerebat; matrimonium non erit: quae species pupillae comparanda est; D. 34,9,1,1 (Marcian. 6 institutionum): Item si quis contra mandata duxerit uxorem ex ea provincia in qua officium aliquid gerit, quod ei ex testamento uxoris adquisitum est; D. 23,2,65 (Paul. 7 resp.): Respondit mihi placere, etsi contra mandata conrtractum sit matrimonium in provincia, tamen post depositum officium, si in eadem voluntate perseverat, iustas nuptias effici. 
Tal y como se deduce del contenido de las fuentes ${ }^{37}$, por intervención del Senado era subsanable tal ineficacia o nulidad. Para Gayo ${ }^{38}$, este tipo de matrimonio existía pero se consideraba como nulo en cuanto a los efectos que producía por lo que se consideran como matrimonia iniusta, non iusta o non legitima. Se trata pues de un matrimonium contractum pero viciado por error en el sentido de que faltaba la capacidad jurídica de uno de los contrayentes, aunque los hijos eran legítimos.

d) Matrimonio con mujer adúltera: Aludimos al último supuesto de matrimonio ineficaz regulado en las fuentes como matrimonio iniustum y además nulo. El matrimonio con una adúltera era ineficaz pero considerado como existente porque esta clase de matrimonio no le era indiferente al ordenamiento jurídico romano y los hijos habidos, aun considerados como adulterinus, eran reconocidos por el Derecho. En términos generales, se daba este tipo de vínculo conyugal cuando la uxor había violado la fidelidad matrimonial. Para entender esta institución se hace preciso matizar el vocablo latino adulterium. Así, el adulterium era un delito derivado de una relación ilegítima entre hombre y mujer en la que al menos uno de ellos, estaba casado. En cuanto a las sanciones que entrañaba podemos decir que a la mujer culpable (adultera) se le imponían sanciones graves que podían llegar a la muerte y, para el cónyuge adúltero (adulter), existían simples penas pecuniarias. Durante la

37 Las fuentes que regulan esta cuestón son, entre otras, Gai. 1,67-68: Condicionem sequitur qui nascitur, iisdem casibus in potestate eum patris, etiamsi is cuius Romanus sit, non esse plus quam manifestum est; Gai. 1,87: Latinam aut peregrinam uxorem duxerit per ignorantiam, cum eam civem romanam esse crederet, et filium procreaverit, hic non est in potestate eius, quia ne quidem civis romanus est; Gai. 1,75: Ex his quae diximus apparet sive civis romanus peregrinam sive peregrinus civem romanam uxorem duxerit; D. 23,2,16 (Paul. 35 ad edictum): Nepote uxorem ducente et filius consentire debet, neptis vero si nubat, voluntas et auctoritas avi sufficiet. Furor contrahi matrimonium non sinit, quia consensu opus est; sed recte contractum non impedit; D. 23,2,28 (Marcian. 10 institutionum): Si quis in Senatorio ordine agens libertinam habuerit uxorem, Invitam libertam uxorem ducere patronus non potest; D. 23,2,31 (Ulp. 6 ad Leg. Iul. et Pap.): Si Senatori indulgentia Principis fuerit permissum libertinam iustam uxorem habere, potest iusta uxor esse; D. 23,2,37 (Paul. 7 resp.): Libertum curatoris Puellas prohiberi oportet uxorem eandem ducere; D. 23, 2,45 (Ulp. 3 ad Leg. Iul. et Pap.): Qui autem iuravit se patronum, hoc idem non habebir; D. 23,2,48 (Terenc. 8 ad Leg. Iul. et Pap.): Filio patroni in libertam paternam eandemque uxorem idem iuris. Idemque dicendum erit, et si alterius patroni filius vivo altero libertam eorum uxorem duxerit; D. 23,2,62 (Pap. 4 resp.): Mulier liberto viri ac patroni sui mala ratione coniungitur. Tutor, qui rationes curatori reddidit, puellam suam ante constitutum tempus aetatis eius uxorem ducere, nec matrem ex alio matrimonio factam potest.

38 D. 38,11,1 (Ulp. 47 ad edictum) y D. 50,1,37,2 (Callist. 1 de cognitionibus).

(C) UNED. Revista de Derecho UNED, núm. 26, 2020 
República $^{39}$ el vir tenía derecho de dar muerte a la uxor si la sorprendía en adulterio, pero con la Lex Iulia de adulterium se le prohibió al marido matar a la mujer adúltera ${ }^{40}$. En consecuencia, el matrimonio contraído con mujer adúltera era iniustum pero el vir no era castigado por adulterio más que con determinadas penas pecuniarias y los hijos nacidos en tales matrimonios recibían el nombre de adulterinus ${ }^{41}$.

\section{NATURALEZA JURÍDICA DE LAS PROHIBICIONES A CONTRAER IUSTAE NUPTIAE E IMPEDIMENTOS}

El ius conubii se configuró en la época clásica como un requisito positivo esencial para que pudiésemos hablar de matrimonium iustum, y el inconveniente que se plantea es el delimitar aquellas situaciones en las que existía una prohibición o un impedimento para contraer tales nupcias, ya que de ello iba a depender los efectos jurídicos que esa unión pudiera o no producir en el ordenamiento romano. Al ser un requisito formulado negativamente, en el sentido de que la carencia de conubium dificultaba la celebración del matrimonio y producía el nacimiento de los impedimentos matrimoniales, se hace necesario investigar sobre su origen y concepto, en los textos jurídicos con los que contamos. En este sentido, algunos autores ${ }^{42}$, al

39 La sanción contra la infidelidad matrimonial, por parte de la mujer, se daba desde épocas primitivas. Un avance en este tipo de sucesos, fue la quaestio de adulteriis o Tribunal sobre los adulterios porque, mediante la Lex Iulia de adulteriis coercendis de Octavio Augusto del año 18 a.C., se calificaban como crimen cuatro tipo de conductas sexuales contrarias a Derecho, como son: adulterium, lenocinium o alcahuetería, incestum y strupum. (Sobre el crimen de adulteriis, vid. BETANCOURT, F., Derecho Romano Clásico, Sevilla (Editorial Universidad de Sevilla), 1995, p. 413).

40 Algunas fuentes que tratan esta cuestión son D. 23,2,16 (Paul. 35 ad edictum): Teas adulterio factas nec ante, damnationem vivente marito uxores duci posse; D. 48,5,5 (Iul. 86 dig.): Nuptam mihi adulterii ream postulari posse in priore matrimonio commissi, dubium non est, quum aperte lege Iulia adulteriis coercendis caveatur; D. 50,16,11 (Gai. 1 ad edictum provinciale): Creditorum appellatione non hi tantum accipiuntur, qui pecuniam crediderunt, sed omnes, quibus ex qualibet causa debetur; D. 50,16,22,5 (Gai. 4 ad edictum provinciale): Fugitivus est non is, qui solum consilium fugiendi a domino suscepit, licet id se facturum iactaverit, sed qui ipso facto fugae initium mente deduxerit; nam et furem, adulterum, aleatorem, quamquam aliqua significatione ex animi 38.

41 NÚNEZ PAZ, M. I., Consentimiento matrimonial y divorcio en Roma, cit., p.

42 En este sentido, vid. VOLTERRA, E. La Conception du mariage d'après les juristas romains, Padua, 1940, p. 372 en NÚÑEZ PAZ, M. I., Consentimiento matrimonial y divorcio en Roma, cit., p. 28-29. 
definir el matrimonio clásico, aportan implícitamente los elementos necesarios para su válida constitución así como alude a la necesidad de que no existiese impedimento alguno. El matrimonio romano, pues, existía jurídicamente cuando un hombre y una mujer libres, con conubium y que carecían de impedimento legal alguno, establecían una relación conyugal con la voluntad efectiva y continua de estar unidos duraderamente en matrimonio.

Partiendo de esta definición vamos a detenernos en el origen del vocablo "impedimento" porque esta palabra encuentra su raíz latina en impedimentum que se traduce por estorbo, limitación o prohibición para realizar un determinado acto. En general, si lo aplicamos al campo del Derecho, nos referimos al obstáculo impuesto a la realización o validez de un determinado negocio jurídico, pero cuando nos referimos al matrimonio, ello quiere significar aquellas circunstancias de orden diverso (física, legal o espiritual) que hacen imposible el matrimonio entre dos personas. De esta manera, se comprende el alcance del conubium entendido como capacidad jurídica para contraer matrimonio válido, por no existir obstáculo derivado de la condición de las personas, o de su situación social o parentesco ${ }^{43}$. Trabas, dificultades, prohibiciones, o ausencia de requisitos esenciales son expresiones que hacen referencia a una misma idea, esto es, la imposibilidad de contraer válidamente un vínculo matrimonial durante la vigencia del Derecho Romano clásico, por no reunirse las notas necesarias para ello. Sin embargo, como veremos gran parte de la doctrina, consideran que impedimentum es una palabra cuyo significado completo no se alcanza durante la vigencia del Derecho Romano clásico sino posteriormente con el Derecho Canónico. Así, algunos autores ${ }^{44}$ sostienen que el término impedimentum es propio del Derecho Canónico y lo define como aquellos motivos de varia índole (éticos, políticos, sociales, religiosos) que determinaron una suerte de requisitos que se caracterizan por estar formulados de modo negativo, y son los que actualmente se denominan como impedimentos. Por su parte, Panero (2000, p. 295) también mantiene el origen canónico del término impedimento y le atribuye una formulación negativa que se traduce por prohibición, esto es, se trata de un requisito formulado negativamente que obstaculiza la celebración de todo vínculo conyugal realizado conforme al Derecho Romano clásico.

43 GUTIÉRREZ-ALVIZ, F., Diccionario de Derecho Romano, Madrid (Reus), 1982 , p. 157 y 285.

${ }_{44}$ IGLESIAS, J., Derecho Romano. Instituciones de Derecho Privado, Barcelona (Editorial Ariel), 1972, p. 552. 
De este modo, Bonfante (1929, p. 185) subraya la esencia de estas dificultades a contraer matrimonium iustum y las califica expresamente de requisitos determinados de un modo negativo por la ausencia de ciertas condiciones, por lo que en las Escuelas se usa el concepto de impedimentos matrimoniales. Interesantes resultan, a su vez, las palabras del profesor Betancourt (1995, p. 406) quien al tratar el vínculo marital parte de la base de que el matrimonium era una situación social de hecho (factum) y, por este motivo, el Derecho Romano sólo contempla un sistema de prohibiciones de ius divinum (fas) y de tipo social, pero no un sistema completo de impedimentos como existe en el Ius Canonicum.

A tenor de lo afirmado y, una vez analizado el vocablo impedimentum, vamos a delimitar cuál es la naturaleza jurídica y qué efectos produce en el ordenamiento romano clásico. Podemos decir que son prohibiciones matrimoniales que obstaculizan la normal convivencia de los contrayentes y, a diferencia de la regulación canónica, no suponen la capacidad general de contraer matrimonio sino más bien la ausencia de la capacidad jurídica de los cónyuges. En este punto, Corbett (1969, p. 24), al hacer referencia a la capacidad y condiciones para que existiese un matrimonio justo, define al conubium en relación con las limitaciones que podían darse. Expresamente dice así: "Conubium is said to exist between a man and a woman when they are capable of legal intermarriage. Under absence of conubium the compiler of Ulpian's Regulae treats such various obstacles to marriage as foreign citizanship, slavery, and blood relationship within the prohibited degrees. Modern commentators add differences of rank and status, indeed all relative disabilities as distinc from the absolute obstacles such as absence of consent and impuberty". Por concretar lo anterior, se puede afirmar que la naturaleza jurídica de esta institución se entiende si consideramos las limitaciones matrimoniales como prohibiciones para contraer justas nupcias. De este modo se observa expresamente cuando algún autor ${ }^{45}$, al definir al matrimonio clásico, aporta implícitamente los requisitos positivos y negativos para su válida constitución; por lo que para que se considere matrimonio, no debe existir impedimento legal alguno.

De esta manera, podemos entender el sentido de esta institución puesto que no tendrán las mismas consecuencias un matrimonio contraído contra las prohibiciones de la época clásica, que aquel otro llevado a cabo posteriormente. La razón de estas diferencias se

45 VOLTERRA, E. La Conception du mariage d'après les juristas romains, Padua, 1940, p. 372 en NÚNEZZ PAZ, M. I. Consentimiento matrimonial y divorcio en Roma, cit, p. 28-29. 
encuentra en el cambio de mentalidad respecto a lo que en Roma se entendía por ius conubii. Así Volterra (1986, p. 649), al investigar acerca de las prohibiciones e impedimentos del vínculo conyugal, distingue entre los efectos jurídicos que se producen en cada periodo histórico del Derecho Romano. En su obra sostiene que, el matrimonio clásico que adoleciese de una prohibición para contraer el vínculo, se consideraba como una situación de hecho contraria a la existencia de iustae nuptiae por la carencia de conubium. En este punto, tal prohibición matrimonial se traduce por denegación del derecho a contraer matrimonio. Sin embargo, para el matrimonio postclásico los impedimentos alcanzan la falta de algunos requisitos exigidos en el Derecho clásico para la existencia de conubium entre los cónyuges.

Como avanzábamos, nosotros utilizaremos el término "impedimento" para referirnos a tales inconvenientes o dificultades matrimoniales ya que, a pesar de que la doctrina es unánime en considerar el vocablo como propio del Derecho Canónico, existen fuentes que lo utilizan desde el punto de vista literal del término. En base a estas premisas, se definen ${ }^{46}$ los impedimentos matrimoniales como aquellas circunstancias de orden diverso, física, legal o espiritual, que hacen imposible el matrimonio entre dos personas y, a continuación, se relacionan con los distintos textos jurídicos que tratan esta sobre esta materia ${ }^{47}$. A pesar de que las fuentes hablan a veces de impedimentum por tratarse de una prohibición legal de la convivencia matrimonial en sentido distinto de los impedimentos matrimoniales de Derecho Canónico, autores de la talla de Kunkel (1965) o Á.D’Ors (1977) utilizan expresiones como "obstáculos o prohibiciones que no permitían el matrimonio" en lugar de usar el vocablo "impedimento". La razón se encuentra en que este último término es técnicamente canónico y no se entiende dentro del Derecho clásico. Expresamente Á. D’Ors (1977) matiza esta cuestión al utilizar "prohibiciones matrimoniales" en vez de "impedimentos" por considerar que se adecuan mejor a la concepción romana del matrimonio, ya que no existió propiamente en Derecho Romano un sistema de impedimentos, pero si de prohibiciones.

Del mismo modo, Domingo (1989, p. 11 ss.) investiga acerca de la naturaleza de las prohibiciones y advierte que en el Derecho Romano no existió stricto sensu un sistema de impedimentos, como se da, por ejemplo, en el Derecho Canónico. Y así sólo hace referencia a las "Prohibiciones matrimoniales" o a la "Prohibición de con-

46 GUTIÉRREZ-ALVIZ, F., Diccionario de Derecho Romano, cit., p. 285.

47 A modo de ejemplo, vid. Gai. 1,58-64 e IJ. 1,10,1-2. 
traer matrimonio o nupcias”. Otra expresión similar la aporta Baquero (1987, p. 307 ss.) quien directamente le llama "Prohibición del ius conubii". Adentrándonos en la esencia de esta institución Schulz (1960, p. 108 ss.), quien había considerado al Derecho clásico como el logro más impresionante del genio jurídico de Roma, se refiere además a la existencia de impedimentos durante esta etapa. Por su parte, también hace uso del vocablo impedimentum Robleda (1970, p. 179 ss.), quien aporta toda una clasificación de estos y los considera como la ausencia de conubium desde época preclásica a postclásica. Del mismo modo, hace alusión al impedimento de ligamen, de consanguinidad, de cognación legal. Además, define expresamente la afinidad y habla del impedimento de afinidad tal y como aparece en las fuentes ${ }^{48}$. Por último, añade otros impedimentos como los introducidos por las Leyes Iulia y Papia: el impedimento a causa del adulterio, del servicio militar, contra mandata, por razón de la tutela, impedimento del luto, de colonato, entre judíos y cristianos, de cognación espiritual y, para acabar, de orden sagrada y voto de castidad. En definitiva, afirma que todos los impedimentos matrimoniales reseñados y no había otros en Derecho Romano se entendían, según creemos, fuera de uno (el por razón de luto, cual arriba dijimos), bajo la sanción de nulidad.

Tal y como argumentamos a la hora de abordar el concepto de impedimento matrimonial, Bonfante (1929, p. 185) dedica en su obra un apartado al fundamento de esta institución y reflexiona sobre los requisitos e impedimentos del matrimonio. Definiendo a estos últimos como otros requisitos determinados de un modo negativo por la ausencia de ciertas condiciones, y sigue diciendo que los impedimentos nacen de motivos de orden ético, social y político, y en la nueva época también de intolerancia religiosa. Una interesante interpretación es la que hace Nuñez $\left(1988\right.$, p. 37) ${ }^{49}$ al sostener que la terminología utilizada, es decir el vocablo impedimenum, puede dar lugar a confusiones si nos referimos tanto a la época clásica como a la postclásica debido a la influencia del Derecho Canónico. Sin embargo, se puede usar esta palabra, en cualquier período histórico, para aportar claridad y funcionalidad a la hora de analizar la materia y comprender su naturaleza. Estas afirmaciones se deben a su consideración como circunstancias modificativas del conubium en época clásica e impedimentos, posteriormente. Bajo estas premisas, Volterra (1986, p. 649 ss.) utiliza indistintamente expresiones

48 D. 38,10,4,3 (Mod. 12 pandectarum).

49 En este sentido, considera que todos los impedimentos conllevan la inexistencia del matrimonio en época clásica y la nulidad en la postclásica. 
como "requisito negativo", "ausencia de conubium", "prohibición de contraer nupcias" e "impedimentos matrimoniales", opción que parece acertada y técnicamente correcta para comprender el fundamento jurídico de esta institución. El profesor Falçao (1973, p. 11 ss.) añade otras expresiones equivalentes como son "prohibiciones matrimoniales", y Gómez (1987, p. 98) habla de "detracción del connubium", "privación del connubium clásico" e, incluso, de "quitar el connubium".

A tenor de los argumentos doctrinales y propios, expuestos anteriormente, podemos afirmar que si bien no es fácil aportar una definición jurídica que reúna todos los elementos del concepto de impedimentum a lo largo de la historia de Roma, el análisis comparativo que hemos realizado sobre la esencia y naturaleza de tales prohibiciones desde el Derecho clásico hasta el Canónico, nos sirve de base para comprender su regulación en las fuentes y, en especial, la sistematización de los distintos tipos de impedimentos matrimoniales aportados por la doctrina a través de sus investigaciones.

\section{CONCLUSIONES}

Con la realización del presente trabajo, hemos analizado el alcance jurídico de los conocidos en Roma como iniustum matrimonium, considerados como tal por no cumplir con los requisites necesarios como para conformar un matrimonio romano legal con plenos efectos jurídicos para el ordenamiento romano. Una mera lectura del título de nuestra investigación, esto es, "Matrimonios ilegales -inexistentes o nulos- desde la legislación matrimonial de Augusto hasta Constantino I", nos lleva a destacar la importancia de las leyes matrinoniales promulgadas por el emperador Augusto, su idea de romanidad desde diferentes ámbitos, los tipos de matrimonios ilegales y su consideración jurídica, así como su evolución y derogación parcial ya con el emperador Constantino I.

Lo que consideramos que, en un primer momento, adquiere importancia si tenemos presente que en aún hoy España no existe una legislación matrimonial específica y debemos acudir a los concretos artículos del Código Civil español que lo regulan. A modo de ejemplo, cabe señalar el artículo 44 dispone expresamente que: "El hombre y la mujer tienen derecho a contraer matrimonio conforme a las disposiciones de este Código. El matrimonio tendrá los mismos requisitos y efectos cuando ambos contrayentes sean del mismo o de diferente sexo". Precepto redactado por la Ley 30/1981, 7 julio, por la que 
se modifica la regulación del matrimonio en el Código Civil y se determina el procedimiento a seguir en las causas de nulidad, separación y divorcio, así como posteriormente el segundo párrafo fue introducido por el apartado uno del artículo único de la Ley 13/2005, de 1 de julio, por la que se modifica el Código Civil en materia de derecho a contraer matrimonio.

Volviendo a las mencionadas leyes matrimoniales augusteas, al comienzo de nuestra investigación, se ha demostrado cómo tanto la Lex Iulia de maritandis ordinibus como la Lex Papia Poppaea nuptialis formaron un solo texto denominado Lex Iulia et Papia Poppaea (9 d.C.) cuya finalidad primordial fue la restauración de la familia romana sobre la base de las tradiciones y de los mores maiorum para desarrollar una política legislativa que favoreciesen las uniones matrimoniales lícitamente contraídas y la procreación. La influencia de las mismas ha sido puesta de manifiesto por la communi opinio quienes, a pesar de las críticas recibidas, señalan que las innovaciones introducidas por estas leyes son de gran importancia para el Derecho clásico y crean un imperativo matrimonial. No obstante, a partir del siglo IV d.C., comienzan a caer en desuso debido a la influencia del Cristianismo y a la implantación de nuevos valores sociales quedando en el Derecho justinianeo algunos restos insignificantes de ellas.

Lo anterior nos ha llevado, en un segundo momento de nuestro trabajo, al estudio de los matrimonios romanos ilegales, esto es, aquellas uniones conyugales carentes del conubium y que, por ende, no producían efectos jurídicos y se consideraban como un matrimonium iniustum. En este punto, cabe resaltar importancia del ius conubii concebido como el derecho y la capacidad jurídica para contraer un matrimonio legal y conforme al Derecho Romano clásico. La falta de este requisito determinaba, por ende, la calificación de "unión extramatrimonial" por no cumplir con uno de los elementos esenciales que caracterizaba a todo matrimonium iustum. A nuestro entender el estudio detallado del matrimonio romano y en concreto las escasas fuentes que regulan la capacidad jurídica, puede servirnos para comprender de qué manera nacerán en época clásica determinadas prohibiciones a contraer un matrimonium conforme a derecho y cuáles eran sus efectos. Para ello, resulta necesario resaltar cómo el matrimonio romano clásico no tenía la consideración jurídica de contrato pues requería no sólo de la existencia de una convivencia marital sino también de un consentimiento continuado prestado libremente entre los contrayentes. 
Asimismo, se ha abordado la problemática jurídica que suscita la falta de sistematización legal y doctrinal que existe entre las prohibiciones matrimoniales debido a la disparidad de textos que regulan tal cuestión. De ahí que hayamos aportado una clasificación propia de las limitaciones al matrimonium fruto del análisis pormenorizado de las fuentes que regulan esta materia en sus distintas épocas; así como que hablemos de matrimonium iniustum cuando no se cumplían los requisitos exigidos por el Derecho Romano como para ser considerados como matrimonios legítimos. Por lo anterior, a la hora de exponerlos, hemos preferido diferenciar entre: $1^{\circ}$ Los matrimonios iniustum inexistentes -distinguiendo, a su vez, entre matrimonio del demente, matrimonio simulado, y matrimonio por miedo-; y $2^{\circ}$ los matrimonios nulos o ineficaces -y, dentro de este segundo criterio, cabe apreciar el matrimonio informe, el matrimonio contra mandata; el matrimonio de cives con peregrina carente de la civitas o con libertas, y el matrimonio con mujer adúltera-. Pues todos ellos presentan supuestos distintos y en las fuentes no existe una diferenciación clara entre ambas clases de matrimonios injustos, lo que entendemos justifica que debamos acudir a la consideración del vínculo conyugal como un hecho social con relevancia jurídica y no meramente una res facti.

Finalmente, se ha examinado el alcance del término impedimentum pues el mismo tiene su origen en el Derecho Canónico aunque, existen fuentes anteriores que lo utilizan en sentido genérico para aludir al conjunto de restricciones o limitaciones que imposibilitaban celebrar válidamente un matrimonio legítimo. Por tanto, a lo largo de nuestra exposición hemos hecho referencia tanto a la ausencia de conubium como a la de impedimentum según se trataba en el Derecho clásico o justinianeo. Hecho que consideramos que justifica la necesidad de una investigación específica sobre esta cuestión, así como el interés por tratar la evolución jurídica de los impedimentos matrimoniales.

\section{REFERENCIAS BIBLIOGRÁFICAS}

\section{A. Bibliografía}

Betancourt, F., Derecho Romano Clásico, Editorial Universidad de Sevilla, Sevilla, 1995.

CoBertt, P., The Roman Law of Marriage, Oxford, 1969. 
D’Ors, A., Derecho Privado Romano, Pamplona (Editorial Servicio de Publicaciones de la Universidad de Navarra), 1977.

Del Castillo, A., "La emancipación de la mujer romana en el S. I d.C.”, Granada, 1976, en NÚÑEZ PAZ M. I., Consentimiento matrimonial y divorcio en Roma, Salamanca (Ediciones Universidad de Salamanca), 1988.

Domingo, R., La Legislación Matrimonial de Constantino, Pamplona (Editorial Universidad de Navarra), 1989.

FALÇAO, M., Las prohibiciones matrimoniales de carácter social en el Imperio Romano, Editorial Servicio de Publicaciones de la Universidad de Navarra, Navarra, 1973.

Fernández Baquero, M. E., Repudium-Divortium. Origen y Configuración jurídica hasta la Legislación matrimonial de Augusto, Editorial Universidad de Granada, Granada, 1987.

Gómez RuIz, C., El divorcio y las Leyes augusteas, Editorial Secretariado de Publicaciones de la Universidad de Sevilla, Sevilla, 1987.

GutiérRez-Alviz, F., Diccionario de Derecho Romano, Madrid (Reus), 1982.

Iglesias, J., Derecho Romano. Instituciones de Derecho Privado, Barcelona (Editorial Ariel), 1972.

Kunkel, W., Derecho Privado Romano, Barcelona, 1965.

NúÑEz PaZ, M. I., Consentimiento matrimonial y divorcio en Roma, Salamanca (Ediciones Universidad de Salamanca), 1988.

Orestano, R., La Struttura giuridica del matrimonio romano, del Diritto Clásico al Diritto Giustinianeo, Roma, 1940.

Panero, R., Derecho Romano, Tirant Lo Blanch, Valencia, 2000.

Puchta, G. F., Cursus der Institutionem, Vol. II., Leipzig, 1875.

RobledA, O., El matrimonio en Derecho Romano. Esencia, requisitos de validez, efectos, disolubilidad, Librería Editrice Università Gregoriana, Roma, 1970.

Schulz, F., Derecho Romano clásico, Bosch Casa Editorial, Barcelona, 1960.

Treggiari, S., Roman Marriage. Iustes Coniuges from the Time of Cicero to the Time of , Oxford, 1993.

Volterra, E., Instituciones de Derecho Privado Romano, Madrid (Civitas), 1986. 
Volterra, E., "Iniustum matrimonium", GROSSO, G. (Coord.), Studi in Onore di Gaetano Scherillo, II, Istituto Editoriale Cisalpino-La Goliardica, Milano, 1972, pp. 441-470.

\section{B. Fuentes legislativas y/o electrónicas [Recuperado: Noviembre, 2019]}

Del Castillo, A., "Legislación romana y liberación femenina: Una relación inconsciente”, LCENTVM, VII-VIII, 1988-89 [En línea]: https://rua.ua.es/dspace/bitstream/10045/4435/1/Lucentum_07-08_07.pdf

Maldonado de Lizalde, E., "Lex Iulia de Martindais Ordinibus. Leyes de familia del emperador César Augusto", UNAM, pp. 535-645 [En línea]: http://historico.juridicas.unam.mx/publica/librev/rev/hisder/cont/14/dr/dr13.pdf

Muñoz Catalán, E., "Las uniones extramatrimoniales ante la falta de conubium: Fundamento jurídico de los impedimentos matrimoniales en la Roma clásica”, Arias Montano: Repositorio institucional de la Universidad de Huelva. Colección de Tesis Doctorales, 2013, pp. 339 ss. [En línea]: _ http://rabida.uhu.es/dspace/ bitstream/handle/10272/6457/Las_uniones_extramatrimoniales. pdf? sequence $=2$

Muñoz Catalán, E., "Consentimiento viciado o error en los matrimonios de conveniencia celebrados desde la antigua Roma”, RJUA: Revista Jurídica de la Universidad Autónoma de Madrid, 27, 2013 [En línea]: http://www.uam.es/otros/rjuam/numeros_publicados. html

Código Civil español (Edición vigente hasta el 22 de Julio de 2014) [En línea]: http://noticias.juridicas.com/base_datos/Privado/ cc.html

CONSTITUCIÓN ESPAÑOLA DE 1978 [En línea]: https://www.boe.es/buscar/ act.php?id=BOE-A-1978-31229

LEY 30/1981, 7 julio, por la que se modifica la regulación del matrimonio en el Código Civil y se determina el procedimiento a seguir en las causas de nulidad, separación y divorcio [En línea]: https:// www.boe.es/buscar/doc.php?id=BOE-A-1981-16216

LEY 13/2005, de 1 de julio, por la que se modifica el Código Civil en materia de derecho a contraer matrimonio [En línea]: https:// www.boe.es/eli/es/l/2005/07/01/13 
Textos Jurídicos De DeRecho Romano [En línea]: http://bib.us.es/derecho/recursos/pixelegis/areas/derechoRomano-ides-idweb.html 